\title{
Precipitation Behavior of $\sigma$ Phase in Ultra-Supercritical Boiler Applied HR3C Heat-Resistant Steel
}

\author{
Tie-Shan Cao ${ }^{1,2} \cdot$ Cong-Qian Cheng ${ }^{1} \cdot$ Jie Zhao ${ }^{1} \cdot$ Hui Wang ${ }^{1}$
}

Received: 28 June 2018 / Revised: 12 December 2018 / Published online: 1 March 2019

(C) The Chinese Society for Metals (CSM) and Springer-Verlag GmbH Germany, part of Springer Nature 2019

\begin{abstract}
The precipitation kinetics of $\sigma$ phase in commercial HR3C heat-resistant steel during aging at $650-800{ }^{\circ} \mathrm{C}$ was studied in the paper. Through morphology, composition and structural analyzing on the second phase in the HR3C steel, it was confirmed that the precipitations after aging were mainly $\mathrm{NbCrN}, \mathrm{M}_{23} \mathrm{C}_{6}$ and $\mathrm{FeCr}$ type $\sigma$ phase. The time-dependent mass change of the three precipitated phases showed that the linearly increased $\sigma$ phase after aging at $750{ }^{\circ} \mathrm{C}-2000 \mathrm{~h}$ was transformed from $\mathrm{NbCrN}$ phase or $\mathrm{M}_{23} \mathrm{C}_{6}$ phase. According to the calculation on the volume fraction of electrolytically dyed $\sigma$ phase, the time-temperature transformation (TTT) curve for $\sigma$ phase at $1 \mathrm{vol} \%$ in two kinds of commercial HR3C steel (different in grain size) was obtained and analyzed. The nose of the TTT curve was located at around $750{ }^{\circ} \mathrm{C}$ for the two kinds of HR3C steel, and the larger grain size HR3C steel displayed a inhibit effect on the precipitation of $\sigma$ phase. The impact energy of the $\mathrm{HR} 3 \mathrm{C}$ steel after aging at $700{ }^{\circ} \mathrm{C}$ decreased obviously with the fracture mechanism changing from ductile fracture to intergranular brittle fracture, which was considered to be related to the density of $\sigma$-brittle phase after aging.
\end{abstract}

Keywords Heat-resistant steel $\cdot$ Aging precipitation $\cdot \sigma$ Phase $\cdot$ TTT curve

\section{Introduction}

HR3C (25Cr-20Ni-Nb-N) steel was a successfully developed austenitic heat-resistant steel through adding $0.25-0.6 \% \mathrm{Nb}$ and $0.15-0.35 \% \mathrm{~N}$ to $25 \mathrm{Cr}-20 \mathrm{Ni} \mathrm{TP} 310 \mathrm{H}$ steel. Due to the effects of solid solution strengthening and precipitation strengthening, the HR3C heat-resistant steel has good high-temperature creep strength, high-temperature oxidation and flue gas corrosion resistance [1-3] and has been applied to manufacture superheater and reheater components whose service temperature is not exceeding $700{ }^{\circ} \mathrm{C}$ [4]. The phase precipitation behavior of HR3C heat-resistant steel during service has attracted the attention of scholars. At present, a large number of research results indicate that

Available online at http://link.springer.com/journal/40195

Jie Zhao

jiezhao@dlut.edu.cn

1 School of Materials Science and Engineering, Dalian University of Technology, Dalian 116024, China

2 State Key Laboratory of Structural Analysis for Industrial Equipment, Dalian University of Technology, Dalian 116024, China the types of precipitates in $\mathrm{HR} 3 \mathrm{C}$ style steel during aging or service are mainly $\mathrm{NbCrN}$ ( $\mathrm{Z}$ phase) $[5,6], \mathrm{M}_{23} \mathrm{C}_{6}[7-9]$ and $\mathrm{Nb}(\mathrm{C}, \mathrm{N})[6,10], \mathrm{Cr} 3 \mathrm{Ni} 2 \mathrm{SiC}$ [7] and $\sigma$ phase [5, 11-14]. However, the existence of $\sigma$ phase precipitating in HR3C heat-resistant steel during high temperature exposing is controversial [5, 15].

In iron-based alloys, the presence of $\sigma$ phase will significantly reduce the plasticity, toughness, long-term strength and creep life of the materials [16-18]. The HR3C heatresistant steel is a steel designed to inhibit the precipitation of $\sigma$ phase during the long-term creep [15], and no $\sigma$ phase was detected in the actual service conditions until now [19, 20]. Hu et al. [19] found no $\sigma$ phase generated in HR3C steel after a $15960 \mathrm{~h}$ operation in a power plants. Yin et al. [20] did not show the existence of $\sigma$ phase in a significant brittle HR3C steel, which has served in an ultra-supercritical unit for $25,000 \mathrm{~h}$. The precipitation of $\sigma$ phase in HR3C steel is more common during the high-temperature aging $[5,14$, 21-23]. Wang et al. [14] found different shape $\sigma$ phase precipitated at the grain boundary in HR3C steel after aging at $700{ }^{\circ} \mathrm{C}$ for more than $10,000 \mathrm{~h}$. Fang et al. [5] discovered the existence of $\sigma$-FeCr phase in the extracted powder of Sumitomo HR3C steel after aging at $750{ }^{\circ} \mathrm{C}$ for $500 \mathrm{~h}$. However, there was no $\sigma$ phase was mentioned by Zhu et al. for HR3C 
steel aging at $650{ }^{\circ} \mathrm{C}$ up to $10,000 \mathrm{~h} \mathrm{[24].} \mathrm{The} \mathrm{existence} \mathrm{of} \sigma$ phase precipitating in HR3C heat-resistant steel during high temperature exposing is controversial.

The formation and growth of $\sigma$ phase in HR3C heatresistant steel will absorb the $\mathrm{Cr}$ element of the surrounding matrix to generate a special area as $\mathrm{Cr}$-depleted region leading to uneven oxidation and corrosion. Moreover, the generation of $\sigma$ phase will decrease the solid solution strengthening effect of the surrounding matrix, and the crack tends to nucleate and expand along the interface between the $\sigma$ phase and the matrix. In general, a large amount of $\sigma$ phase precipitation will reduce the plasticity, toughness, longlasting strength and creep life. Therefore, the precipitation of $\sigma$ phase in the service process needs to be paid enough attention, and then it is important to clarify the precipitation behavior of $\sigma$ phase in HR3C heat-resistant steel.

In the paper, microscopic observation, composition identification and phase analysis were used to confirm the existence of $\sigma$ phase in HR3C steel during various aging process. A method was used to further elaborate the precipitation dynamics of $\sigma$ phase in two kinds of HR3C steel (with different grain size) during aging process. Furthermore, the influence of the $\sigma$ phase precipitation on the impact property of HR3C steel was discussed.

\section{Experimental Method and Material}

In this paper, the as-received HR3C austenitic heat-resistant steel pipes with wall thickness of about $7 \mathrm{~mm}$ and $12 \mathrm{~mm}$ were studied. The final heat treatment was solid solution. The chemical composition of the HR3C austenitic heatresistant steel is shown in Table 1.

With reference to the service temperature of $620-680{ }^{\circ} \mathrm{C}$ for HR3C steel [2, 25], the aging temperatures in the paper were $650,700,750$ and $800{ }^{\circ} \mathrm{C}$. After aging in medium temperature box-type resistance furnace (SX-5-12), the sample was air-cooled. The metallographic sample was polished, and then etched in $10 \%$ oxalic acid aqueous solution with electrolytic parameter of $5 \mathrm{~V}-10 \mathrm{~s}$.

In order to determine the type of precipitates and the variation of $\sigma$ phase in HR3C steel after aging, several aged HR3C steel samples $\left(750{ }^{\circ} \mathrm{C}-2000 \mathrm{~h}\right)$ were extracted in a $10 \mathrm{wt} \%$ hydrochloric acid solution with parameter of $12.5 \mathrm{~V}-20 \mathrm{~h}$ (the cathode was $\mathrm{Al}$ and the anode was the sample). Then, the extracted powder was analyzed through X-ray diffraction analyzer (XRD-6000) under $2 \theta=30^{\circ}-100^{\circ}$ and step speed of $0.02^{\circ} \%$ s. The XRD patterns were further analyzed with software of MDI Jade 6.0. Based on the phase information in the XRD pattern, the content of each precipitated phase was quantitatively analyzed by adiabatic method (according to the PDF card of XRD, the RIR values of $\mathrm{NbCrN}, \mathrm{M}_{23} \mathrm{C}_{6}$ and $\sigma$ phases are 5.91, 2.98 and 2.72, respectively).

The position and the morphology of the precipitates were observed and identified by MEF-4 optical microscope (OM), JSM-5600LV scanning electron microscope (SEM) and Tecnai G220 S-Twin type transmission electron microscope (TEM), and the chemical composition of the precipitated phases was analyzed with the EDS spectrometer, where the TEM sample was prepared with the MTP-1A-type double-jet thinning apparatus, and the double spray was $20 \%$ $\mathrm{HNO}_{3}+80 \% \mathrm{CH}_{3} \mathrm{OH}$, dual-injector voltage was $15 \mathrm{~V}$, double-spray temperature was $0{ }^{\circ} \mathrm{C}$, using nitrogen to prevent sample's oxidation during the preparation.

After the determination of $\sigma$ phase, the precipitation dynamic behavior was analyzed through color metallography. The color metallography was obtained by electrolyzing in $45 \mathrm{~g} / 60 \mathrm{ml} \mathrm{KOH}$ aqueous solution under parameter of $5 \mathrm{~V}-3 \mathrm{~s}$, and then $\sigma$ phase is dyed brownish red, wherever carbides and the austenite are hardly colored according to ASTM E407-2007. The color metallographic structure was observed and collected by MEF-4 optical microscope, and the volume of $\sigma$ phase was semiquantitatively estimated by calculating the relative area of the brownish red color in the metallography. In addition, the equilibrium phase diagram during $550-800^{\circ} \mathrm{C}$ and the time to 1 vol $\% \sigma$ phase transformation at different temperature (time-temperature transformation, TTT) for HR3C steel were calculated.

\section{Results and Discussion}

The microstructure of as-received and $750{ }^{\circ} \mathrm{C}-2000 \mathrm{~h}$-aged HR3C steel is shown in Fig. 1. In Fig. 1a, the grain boundary of as-received HR3C steel is not obvious, indicating a good corrosion resistance due to the less second phase precipitate at the grain boundary. Some granular second phases can be observed in the matrix, and according to previous researches $[5,10]$, they are undissolved $\mathrm{Nb}(\mathrm{C}$, $\mathrm{N}$ ) or $\mathrm{NbCrN}$, which will be further transformed into a stable $\mathrm{NbCrN}$ phase during aging. This is an important factor in maintaining the high creep strength of HR3C steel during service at high temperatures [5]. After aged at $750{ }^{\circ} \mathrm{C}$ for $2000 \mathrm{~h}$, as shown in Fig. $1 \mathrm{~b}$, the grain boundary of HR3C steel is more obvious, which is related to the
Table 1 Chemical composition standard of HR3C steel (wt\%)

\begin{tabular}{lllllllll}
\hline $\mathrm{Cr}$ & $\mathrm{Ni}$ & $\mathrm{Nb}$ & $\mathrm{C}$ & $\mathrm{N}$ & $\mathrm{Mn}$ & $\mathrm{Si}$ & $\mathrm{P}$ & $\mathrm{S}$ \\
\hline $24.00-26.00$ & $17.00-23.00$ & $0.20-0.60$ & $0.04-0.10$ & $0.15-0.35$ & $\leq 2.00$ & $\leq 0.75$ & $\leq 0.030$ & $\leq 0.030$ \\
\hline
\end{tabular}



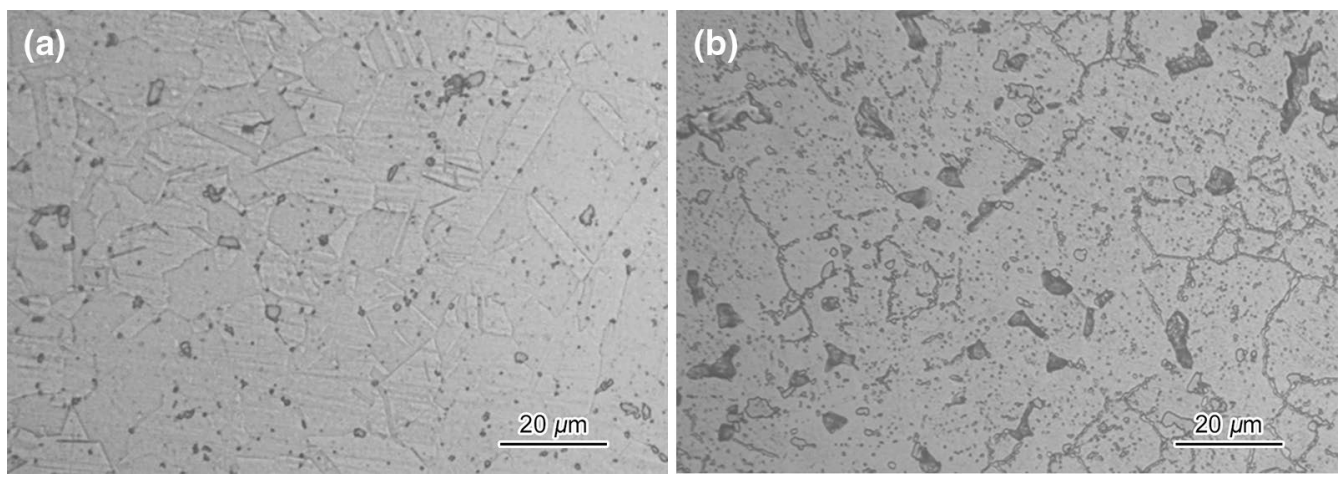

Fig. 1 Microstructure of HR3C steel at a as-received and $\mathbf{b} 750{ }^{\circ} \mathrm{C}-2000 \mathrm{~h}$ aging states

chromium-depleted region formed by the precipitation of the second phase. Besides, Fig. 1b shows more large-sized massive dark precipitates at the grain boundary. The size and scale of the precipitation will have a greater impact on the high-temperature performance of the HR3C steel, so the type of the large precipitated phase in the aged HR3C steel needs to be studied.

(a)
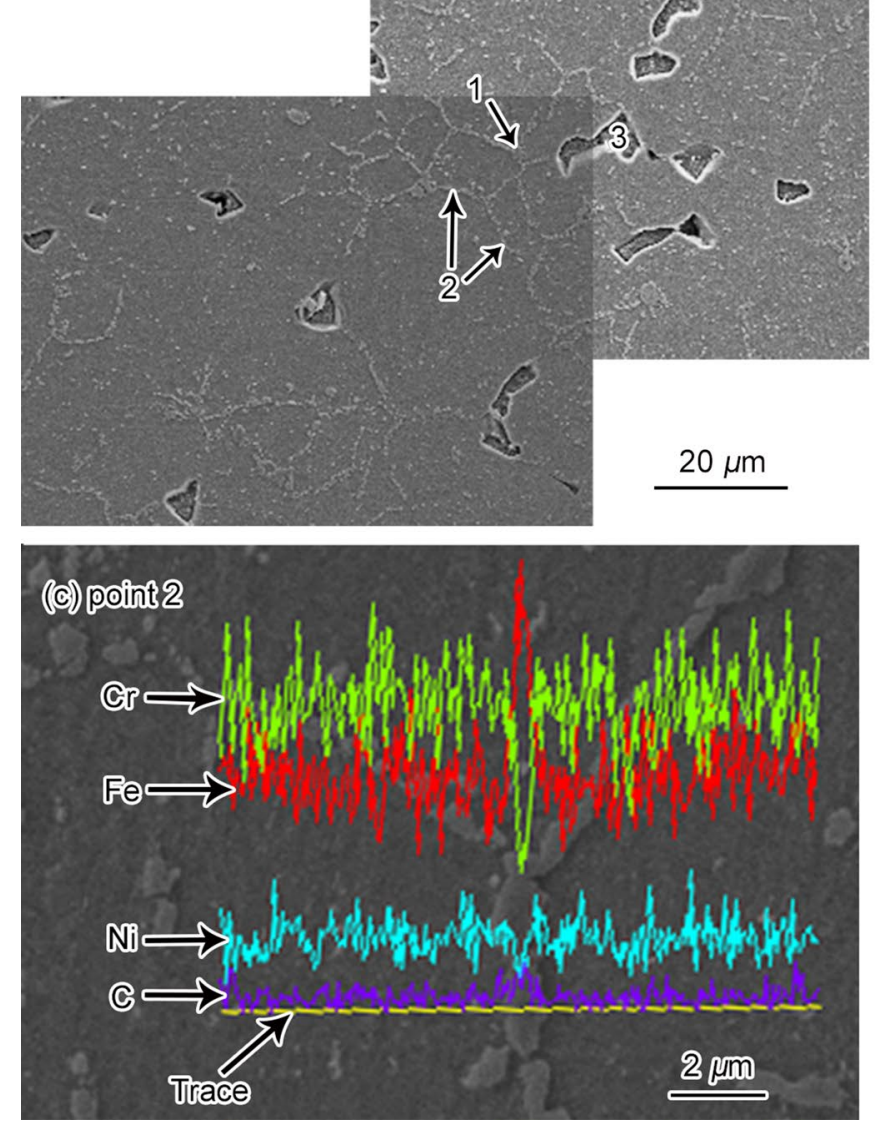

The morphology and composition of the second phases precipitated in $750{ }^{\circ} \mathrm{C}-2000 \mathrm{~h}$-aged HR3C steel are shown in Fig. 2. Figure 2a shows the typical grain boundary phases: The point 1 is $\mathrm{NbCrN}$ phase as the atom ratio of $\mathrm{Nb} / \mathrm{Cr} /$ $\mathrm{N}=21.98: 24.01: 22.92 \approx 1: 1: 1$ according to the EDS analysis in Fig. $2 \mathrm{~b}$; the grain boundary precipitation like point 2 in Fig. $2 \mathrm{a}$ is $\mathrm{M}_{23} \mathrm{C}_{6}$ or other carbides as the content of

\section{(b) point 1}

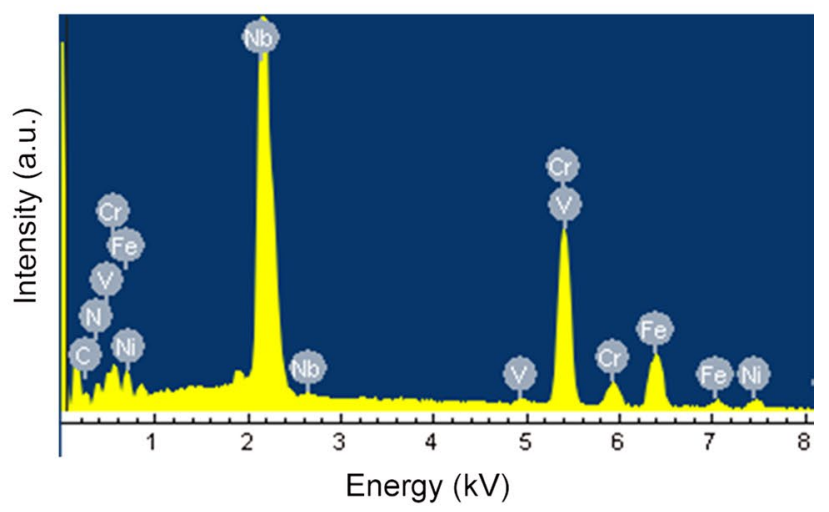

(d) point 3

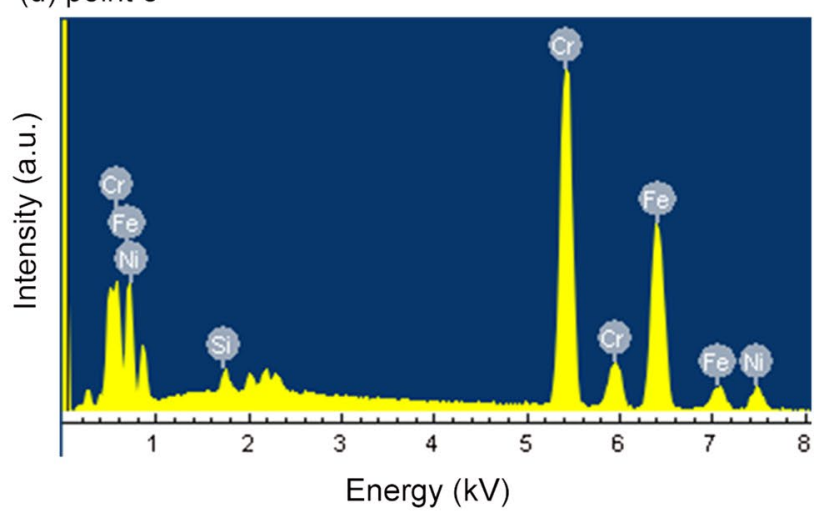

Fig. 2 a SEM and b EDS analysis on the precipitations in $750{ }^{\circ} \mathrm{C}-2000 \mathrm{~h}$-aged HR3C steel 
C element is higher than that of substrate as illustrated in Fig. 2c, and the precipitation of point 3, the large dark phase in Fig. 1b, is more than $10 \mu \mathrm{m}$ and irregular in shape. EDS analysis (Fig. 2d) exhibits a composition of 48.53 at\% $\mathrm{Cr}$, 41.59 at\% $\mathrm{Fe}, 8.34$ at\% $\mathrm{Ni}$ and a small amount of Si (1.54 at\%) elements. The phase attracting attentions with nearly 50 at $\% \mathrm{Cr}$ is commonly regarding as $\sigma$ phase [18], which is harmful to the heat-resistant property.

In order to determine the type of second phases precipitated in $\mathrm{HR} 3 \mathrm{C}$ steel during aging process, the precipitation in the $700{ }^{\circ} \mathrm{C}-2000 \mathrm{~h}$-aged HR3C steel sample was extracted out, and the X-ray diffraction pattern of the extracted powder is shown in Fig. 3. It can be seen from the figure that the second phase of HR3C steel is mainly composed of $\sigma$ phase, $\mathrm{NbCrN}$ and $\mathrm{M}_{23} \mathrm{C}_{6}$ phases after aging treatment. Combined

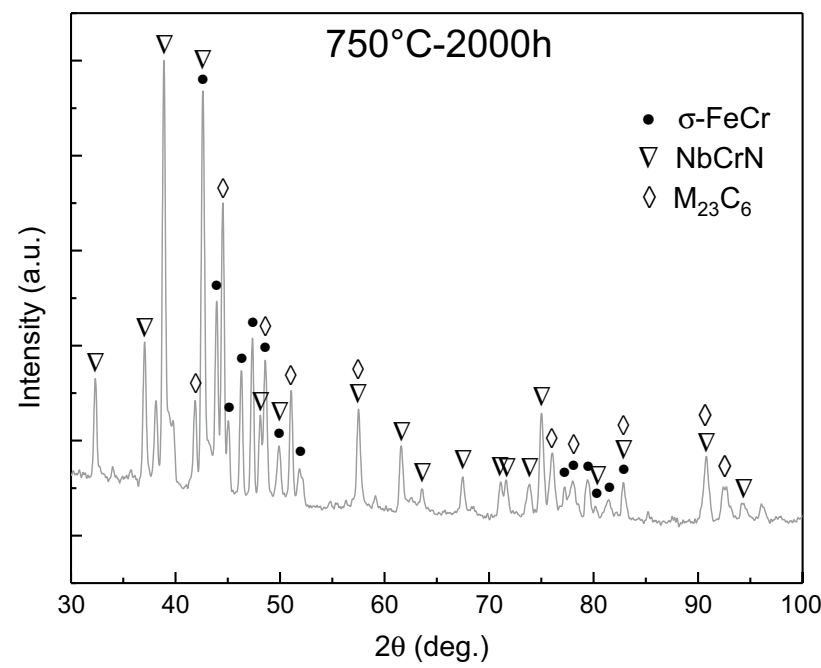

Fig. 3 XRD pattern on the precipitations extracted from HR3C steel aged at $750{ }^{\circ} \mathrm{C}$ for $2000 \mathrm{~h}$

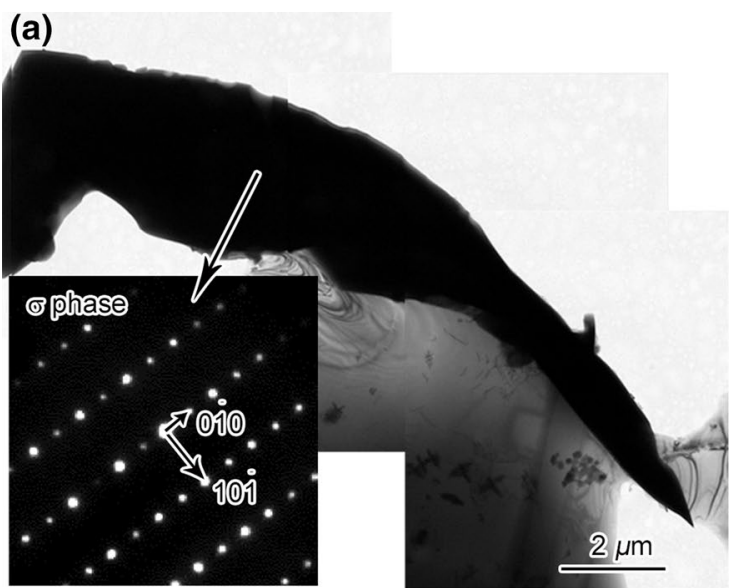

with the results showed in Fig. 2, the irregular dark phase in Fig. $1 \mathrm{~b}$ and Fig. 2a is probably to be $\sigma$ phase.

According to the TEM study in the former work [22], as shown in Fig. 4a, the dark irregular phase in the grain boundary $750{ }^{\circ} \mathrm{C}-2000 \mathrm{~h}$-aged samples is about $10 \mu \mathrm{m}$, which is similar to the massive precipitation presented in the grain boundary in Figs. $1 \mathrm{~b}$ and $2 \mathrm{a}$. The calibration of the SAED diffraction spot determines that the phase is tetragonal sigma phase. The compositional analysis result (Fig. 4b) shows that the $\sigma$ phase mainly composes of $\mathrm{Cr}(49.27 \%), \mathrm{Fe}$ $(42.25 \%)$ and $\mathrm{Ni}(8.48 \%)$ elements. The composition of the phase in Fig. 4a is similar to that of the point 3 in Fig. $2 \mathrm{a}$. Therefore, we confirmed the phase of point 3 in Fig. 2a is $\sigma$ phase. In addition, the aggregation of Si element at the grain boundary, detected in Fig. 2d, will promote the formation and growth of $\sigma$ phase through literature [17, 26, 27].

A large amount of $\sigma$ phase precipitates will cause grain boundary weakness and embrittlement [28]. It is key to know the total amount that precipitated in HR3C steel at high temperature, especially for the service temperature of 600-650 ${ }^{\circ} \mathrm{C}$. As shown in Fig. 5a, the equilibrium phase diagram shows a large amount $\sigma$ phases which exist in the HR3C steel at temperature of $550-750{ }^{\circ} \mathrm{C}$. According to the TTT curve in Fig. 5b, the $\sigma$ phase can be quickly get to a large content of $1 \mathrm{vol} \%$, which affects the properties of HR3C steel. To the temperature at the tip point of " $\mathrm{C}$ "type curve (about $700{ }^{\circ} \mathrm{C}$ ), the transformation time is less than $100 \mathrm{~h}$. Therefore, it is necessary to study the precipitation behavior of $\sigma$ phase in HR3C heat-resistant steel at $600-750{ }^{\circ} \mathrm{C}$ to know the time limitation for service.

In order to study the precipitation kinetics of $\sigma$ phase in the HR3C steel, the precipitated phase for HR3C aging at $750{ }^{\circ} \mathrm{C}$ was extracted and analyzed. The mass percentage change of the precipitations in the extraction powder of HR3C steel (called as relative mass fraction) is

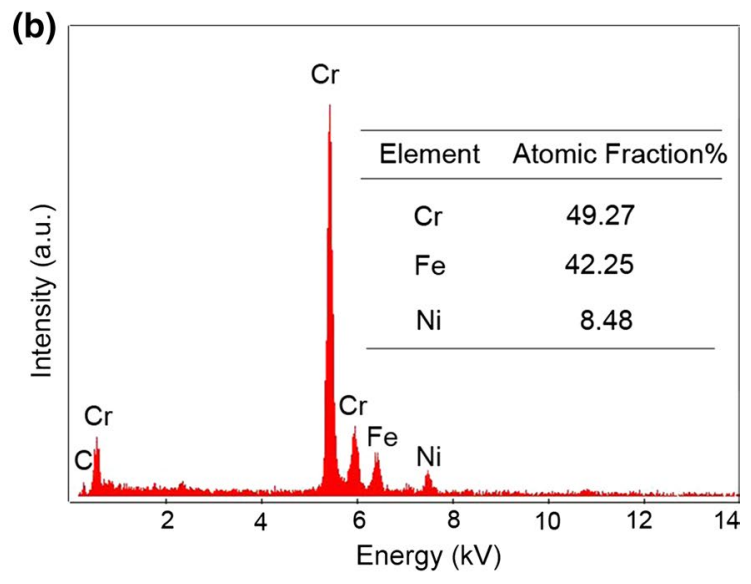

Fig. 4 Analysis on HR3C steel aged at $750{ }^{\circ} \mathrm{C}$ for $2000 \mathrm{~h}$ [22]: a TEM image and SAED pattern (inset); b EDS result of large pieces precipitated phase at grain boundary 

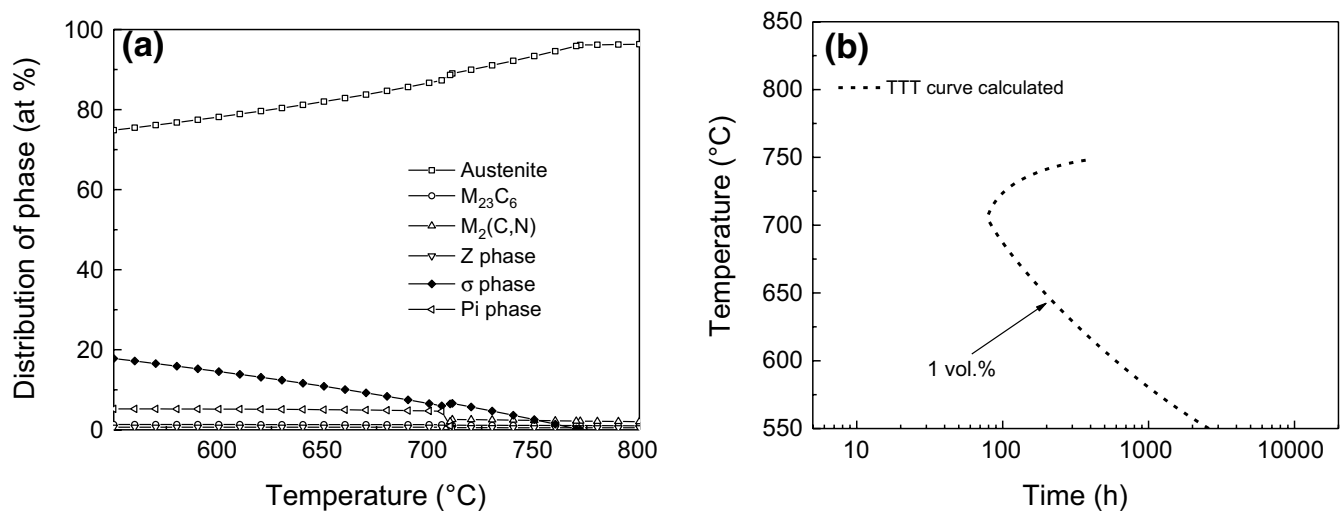

Fig. 5 a Equilibrium phase diagram and b TTT curve of 1 vol\% $\sigma$ phase in HR3C heat-resistant steel

calculated up to $3000 \mathrm{~h}$, and the result is shown in Fig. 6a. It is seen that the relative mass fraction of $\sigma$ phase gradually increases with the aging time, and it has reached $45 \%$ for $3000 \mathrm{~h}$ aging. The variation of the relative mass fraction of $\mathrm{NbCrN}$ phase is opposite to that of $\sigma$ phase, which decreases gradually with the increase in aging time. And the relative mass fraction of $\mathrm{M}_{23} \mathrm{C}_{6}$ carbide is not changed significantly as aging time up to $2000 \mathrm{~h}$, but decreases dramatically as the aging time up to $3000 \mathrm{~h}$.

Through the ratio of the weight of the precipitated phase powder to the weight loss of the sample in the electrolytic extraction experiment, the results of Fig. $6 \mathrm{a}$ can be used to calculate the mass of each phase precipitated in each sample, and the results are shown in Fig. 6b. The $\sigma$ phase increases linearly to nearly $1.0 \mathrm{wt} \%$ during $3000 \mathrm{~h}$ aging at $750{ }^{\circ} \mathrm{C} . \mathrm{M}_{23} \mathrm{C}_{6}$ phase increases from $0.8 \mathrm{wt} \%$ to approximately $1.8 \mathrm{wt} \%$ as the aging time from $500 \mathrm{~h}$ up to $2000 \mathrm{~h}$, and then drops sharply to about $0.7 \mathrm{wt} \%$. $\mathrm{NbCrN}$ phase changes little before $2000 \mathrm{~h}$, but drops obviously as the aging time reaches to $3000 \mathrm{~h}$. Therefore, it is considered that the increased mass fraction of $\sigma$ phase after

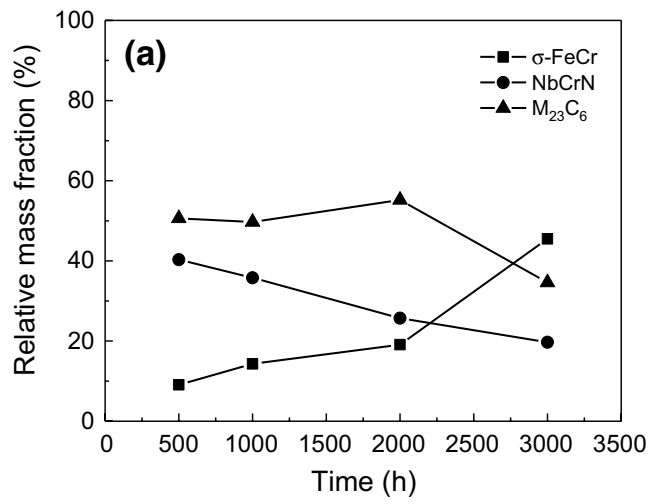

Fig. 6 Precipitation behavior of $\sigma$ phase for HR3C steel aged at $750{ }^{\circ} \mathrm{C}$
$2000 \mathrm{~h}$ aging at $750{ }^{\circ} \mathrm{C}$ may be related to the transformation of $\mathrm{NbCrN}$ phase or $\mathrm{M}_{23} \mathrm{C}_{6}$ carbide or both.

Generally, C element diffuses faster than $\mathrm{Cr}, \mathrm{Mo}, \mathrm{Ni}$ and other elements, then $\mathrm{C}$-containing $\mathrm{Fe}-\mathrm{Cr}-\mathrm{Ni}$ heat-resistant steel tends to precipitate $\mathrm{M}_{23} \mathrm{C}_{6}$ phase rapidly in the grain boundary during aging. It has been pointed out that preprecipitation of carbides such as $\mathrm{M}_{23} \mathrm{C}_{6}$ at grain boundaries will promote sigma phase in situ nucleation on $\mathrm{M}_{23} \mathrm{C}_{6}$, and it is reported that part of $\mathrm{M}_{23} \mathrm{C}_{6}$ turns into $\sigma$ phase after aging at temperatures of $650-850{ }^{\circ} \mathrm{C}$ for a long time [29]. The formation of $\mathrm{NbCrN}$ phase will cause the decrease in the concentration of the surrounding $\mathrm{N}$ elements. It is said that the $\sigma$ phase can only precipitated at the condition that the content of $\mathrm{C}$ and $\mathrm{N}$ is sufficiently low in the matrix [20]. Moreover, the higher $\mathrm{Cr}$ content in $\mathrm{NbCrN}$ may create a favorable condition for the nuclear of $\sigma$ phase and then promotes the precipitation of the $\sigma$ phase.

There are certain errors in the process of extracting powder collection and the calculation of the relative mass fraction of the precipitated phases, but it does not affect much on the trend estimation of the precipitated phases. Considering the estimation error in Fig. 6, it is not used to obtain the TTT

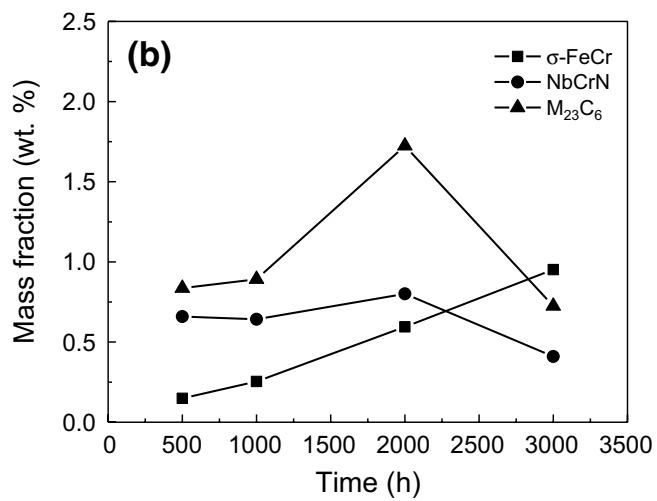


curve for $\sigma$ phase. The dyeing method is used to estimate the content of $\sigma$ phase. As shown in Fig. 7a, $\sigma$ phase in the HR3C steel is dyed brownish red (due to the magnification and image acquisition system, the color of $\sigma$ phase in Fig. 7a is black in visual), while the other phases such as austenite matrix and carbides are not stained. Based on the color difference in Fig. 7a, the relative volume content of the dyed $\sigma$ phase in the HR3C steel is obtained through calculating the ratio of black area to the entire picture. And then, the precipitation volume of $\sigma$ phase in HR3C steel under different aging temperature and time is obtained.

According to the volume content of $\sigma$ phase precipitated at different aging time, the precipitation kinetic of $\sigma$ phase in HR3C steel can be further plotted into TTT curve. As shown in Fig. 7b, the solid square points indicate that the content of $\sigma$ phase is equal or greater than $1 \mathrm{vol} \%$, and the hollow square points indicate that the content of $\sigma$ phase is less than $1 \mathrm{vol} \%$. It is clear that the TTT curve of HR3C steel is a typical "C"-type curve, and the nose of the $\mathrm{C}$ curve is located at about $750{ }^{\circ} \mathrm{C}$. According to the $\mathrm{C}$ curve, a rough deduction of the time of the precipitation of $1 \mathrm{vol} \% \sigma$ phase is more than $50,000 \mathrm{~h}$ for the HR3C steel at an operating temperature $\left(605{ }^{\circ} \mathrm{C}[30]\right)$. This suggests that the reason for not finding the $\sigma$ phase in the service condition may be related to the actual operating temperature and the service time. Comparing to the TTT curve (dash line in Fig. 7b, too) in Fig. 5b, the actual TTT curve is upper-right to the simulated result, which is mainly owing to the difference in grain size caused by the final heat treatment procedure [31].

For further clarifying the effect of grain size, another commercial HR3C heat-resistant steel with a larger grain (naming C steel) was tested for comparison. TTT curve of $\mathrm{C}$ steel is shown in Fig. $7 \mathrm{~b}$ by triangles, and the meaning of solid and hollow triangular points is the same to that of the square points. It can be seen that the junction of the hollow and the solid triangular points is right-moved to that of the

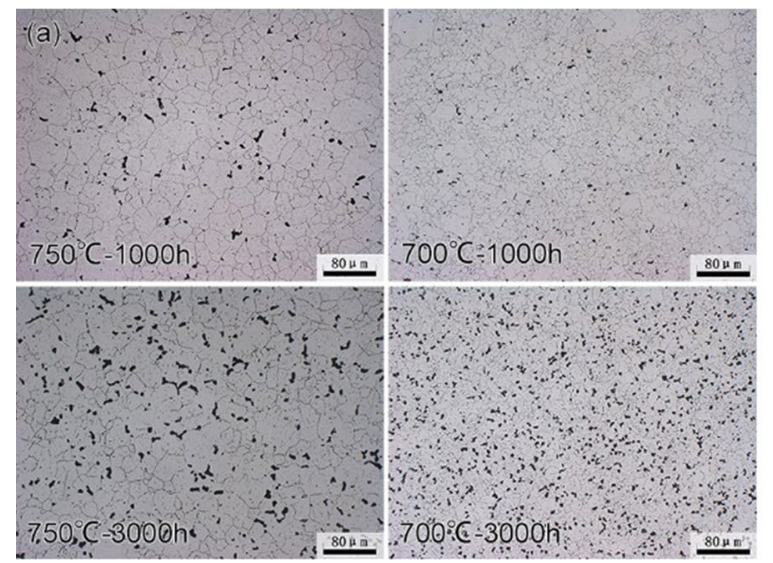

square point. And the precipitation time to 1 vol $\% \sigma$ phase is more than $100,000 \mathrm{~h}$ at $605{ }^{\circ} \mathrm{C}$. These indicate that the transformation time of $\sigma$ phase in coarse grain HR3C steel is delayed or the $\sigma$ phase precipitation in C steel is inhibited. This may provide a reference for the manufacturing of HR3C steel. In addition, it is very rapid for the nucleation and growth of $\sigma$ phase in the HR3C steel studied in the paper. Even aging at $650{ }^{\circ} \mathrm{C}$ (near the service temperature), it takes no more than $4000 \mathrm{~h}$ for $\sigma$ phase precipitating to 1 vol\%. Therefore, more attentions should be paid on the precipitation of $\sigma$ phase in HR3C steel during actual service.

The Charpy impact test showed that the impact energy drops quickly at the first stage of about $0-500 \mathrm{~h}$ and then decreases gradually at the second stage of more than $500 \mathrm{~h}$, as shown in Fig. 8. Through the morphology analysis on the impact fracture, shown as SEM images in Fig. 8, the fracture characteristics changed from toughness to brittleness

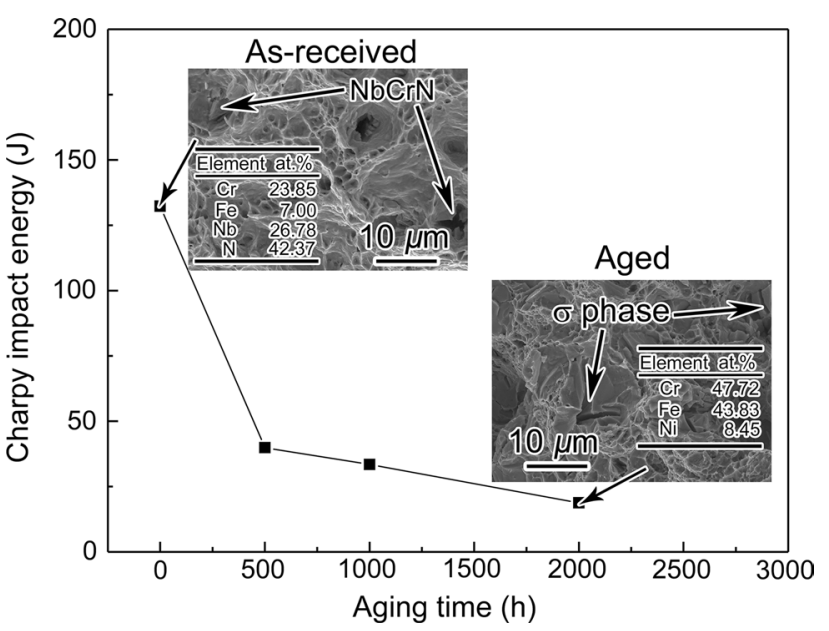

Fig. 8 Charpy impact energy of HR3C steel aged at $700{ }^{\circ} \mathrm{C}$ for different time

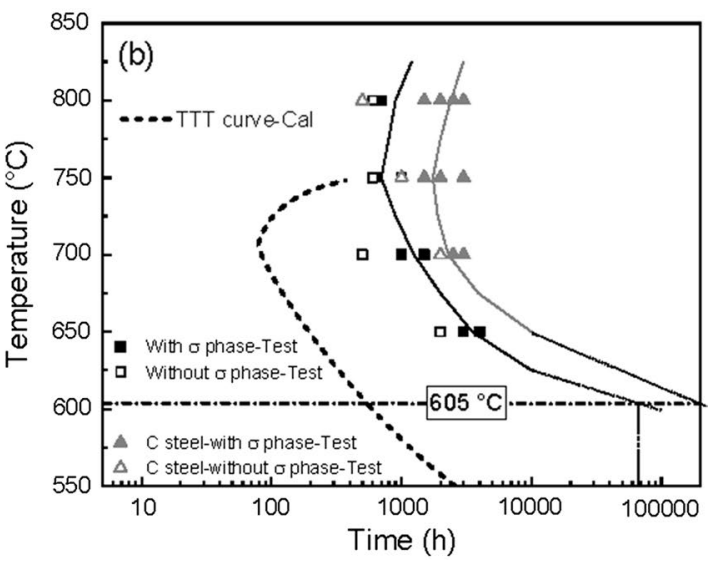

Fig. 7 a OM images of HR3C steel in various states and $\mathbf{b}$ TTT curves of $\sigma$ phase 
fracture. For the as-received HR3C steel, the fracture morphology contains a large amount of dimples and some particles, and EDS analysis shows that these particles are $\mathrm{NbCrN}$ phase. For the aged HR3C steel, the morphology of fracture shows the cracks along the grain boundary, and the irregular shape particles are $\sigma$ phase through composition identification. The dense distribution of $\sigma$ phase in the impact fracture indicates that the $\sigma$ phase plays an important role in the brittleness of HR3C steel.

Although the impact property may not reveal the hightemperature performance directly, the brittleness of HR3C steel during service is still a potential danger for the ultrasupercritical boiler unit, particularly to the situation of normal or abnormal stop and restart operation.

\section{Conclusions}

The paper mainly studies on the confirmation and the precipitation kinetics of $\sigma$ phase in commercial HR3C heatresistant steel during aging, and conclusions are following:

(1) Through morphology observation, composition analysis and structural analysis, the $\mathrm{FeCr}$ type of $\sigma$ phase was confirmed to precipitate at the grain boundary in HR3C steel during aging at $650-800{ }^{\circ} \mathrm{C}$. XRD analysis on the precipitation phase powder found that the main precipitation phases in aged HR3C steel are $\mathrm{NbCrN}$, $\mathrm{M}_{23} \mathrm{C}_{6}$ and $\sigma$-FeCr phase, and the mass change of the three precipitated phases during the aging time shows that the increasing mass of $\sigma$ phase may be related to the transition of $\mathrm{NbCrN}$ or $\mathrm{M}_{23} \mathrm{C}_{6}$ phase.

(2) According to semiquantitative calculation the volume fraction of electrolytically dyed $\sigma$ phase, the time-temperature transformation (TTT) curve for $\sigma$ phase at 1 vol\% in two kinds of commercial HR3C steel (different in grain size) was obtained. The nose of the TTT curve is located at around $750{ }^{\circ} \mathrm{C}$ for the two kinds HR3C steel, and the larger grain size HR3C steel displays a inhibit effect on the precipitation of $\sigma$ phase.

(3) The impact energy of the HR3C steel after aging at $700{ }^{\circ} \mathrm{C}$ decreases obviously with the fracture mechanism changing from ductile fracture to intergranular brittle fracture, and it is considered to be related to the dense distribution of $\sigma$-brittle phase after aging.

Acknowledgements The authors wish to acknowledge the financials support by National Natural Science Foundation of China (No.
U1610256), the National High Technology Research and Development Program of China (The 863 Program) (No. 2015AA034402), and the Dalian University of Technology Fundamental Research Fund (No. DUT17RC(3)010).

\section{References}

[1] H.Y. Yu, J.X. Dong, X.S. Xie, World Iron Steel 10, 42 (2010)

[2] F. Yang, W.M. Li, Y.N. Ren, El. Eq. 5, 41 (2004)

[3] L.P. Tsng, Appl. Energy Technol. 2007, 20 (2007)

[4] X.M. He, C.F. Luo, M.B. Liu, Mater. Heat Treat. 41, 116 (2012)

[5] Y.Y. Fang, J. Zhao, X.N. Li, Acta Metall. Sin. 46, 844 (2010) (in Chinese)

[6] J.Z. Wang, Z.D. Liu, S.C. Cheng, H.S. Bao, Iron Steel 47, 60 (2012)

[7] Y.H. Yang, L.H. Zhu, Q.J. Wang, C.C. Zhu, Mater. Sci. Eng. A 608, 164 (2014)

[8] X. Bai, J. Pan, G. Chen, J. Liu, J. Wang, T. Zhang, W. Tang, Mater. Sci. Technol. 30, 205 (2014)

[9] B. Wang, Z.D. Liu, S.C. Cheng, C.M. Liu, J.Z. Wang, J. Iron Steel Res. Int. 21, 765 (2014)

[10] Y.Y. Fang, Dissertation, Dalian University of Technology (2010)

[11] S. Lalik, Solid State Phenom. 226, 65 (2015)

[12] T.J. Li, F.G. Liu, W.W. Chen, J.H. Zhu, C.X. Wang, L.Y. Liu, B. Wang, Heat Treat. Met. 37, 16 (2012)

[13] Y. Guo, L. Lin, S.F. Hou, B.H. Wang, Electr. Power 45, 42 (2012)

[14] J.Z. Wang, Z.D. Liu, H.S. Bao, J. Iron Steel Res. Int. 20, 54 (2013)

[15] A. Iseda, H. Okada, H. Semba, M. Igarashi, Energy Mater. 2, 199 (2007)

[16] J.M. Joubert, Prog. Mater Sci. 53, 528 (2008)

[17] M.H. Bina, Eng. Fail. Anal. 34, 174 (2013)

[18] P. Hu, Z.W. Wang, Z.G. Li, Guangdong Electr. Power 23, 16 (2010)

[19] J.R. Hu, J.Y. Chen, H.D. Chen, X.W. Yang, S.Z. Mou, Min. Metall. Eng. 32, 110 (2012)

[20] Z. Yin, H. Cai, H.G. Liu, Proc. CSEE 31, 103 (2011)

[21] J. Zhao, H. Wang, C.Q. Cheng, Y.Y. Fang, X.N. Li, Mater. High Temp. 32, 461 (2015)

[22] H. Wang, C.Q. Cheng, J. Zhao, Z. Yang, Acta Metall. Sin. 51, 920 (2015) (in Chinese)

[23] T.J. Li, F.G. Liu, C.X. Fan, B.Y. Yao, Hot Work. Technol. 39, 43 (2010)

[24] C.Z. Zhu, Y. Yuan, J.M. Bai, P. Zhang, J.B. Yan, C.Y. You, Y.F. Gu, Mater. Sci. Eng. A 740-741, 71 (2019)

[25] F. Masuyama, ISIJ Int. 41, 612 (2001)

[26] J.Z. Wang, Z.D. Liu, H.S. Bao, J. Iron Steel Res. Int. 10, 113 (2013)

[27] A.M. Babakr, A. Al-Ahmari, K. Al-Jumayiah, F. Habiby, J. Min. Mater. Charact. Eng. 7, 127 (2008)

[28] T. Sourmail, H.K.D.H. Bhadeshia, Metall. Mater. Trans. A 36, 23 (2005)

[29] K.S. Guan, X.D. Xu, H. Xu, Z.W. Wang, Nucl. Eng. Des. 235, 2485 (2005)

[30] B.S. Du, Y.Z. Wei, Z.W. Zhang, X.M. Li, R. Liu, T. Mater. Heat Treat. 35, 12 (2014)

[31] J. Barcik, Metall. Mater. Trans. A 14, 635 (1983) 